R. Histórla, São Paulo, n. 129-131, p. 133-139, ago.-dez/93 a ago.-dez./94.

\title{
PLACERAS Y MERCADERAS: \\ La versión europea de la vida cotidiana en la antigua Asunción
}

\section{Milda Rivarola *}

RESUMO: Este artigu se preocupa em recuperar a vida cotidiana dus mulheres mercadoras dh cidade de Assunģio a partir th "visão europeia" dos viajantes do século XIX. O pitoresco e o popalay pontuam como elementos expressivos das narrativas destacando a figura da mulber indigena. Ha uma preocupaçâo em clestacar, alén dos hábitus e tradiçôes, as formas de resistência cultural manifestas por estas mulheres "silenciosas e indiferentes ao tempo e as coisas".

PAIAVRAS-CHIAVE: mulheres, comercio, viajantes, violência, cotidiano.

El célebre Mercado-Guazú, instalado desde 1768 en lo que hoy es la plaza de los Héroes, sobrevivió sin grandes variaciones hasta comienzos del presente siglo. De esta cotidiana feria nos restan curiosas descripciones de viajeros europeos, sorprendidos por lo pintoresco y popular del espectáculo en el centro de la ciudad de Asunción.

Bajo la dictadura de Francia, los hermanos Robertson dejaron uno de los primeros testimonios de la bulliciosa actividad matinal. "La más curiosa, interesante y peculiar escena que se presenta en Asunción a los ojos extranjeros es la del Mercado, que se sitúa en una gran plaza cuadrangular. (...) Desde todas las calles que convergen a la plaza venían centenares de mujeres, vestidas sin excepción de blanco. Algunas Iraían en la cabeza tarros de miel; otras, mandioca, o algodón sin tejer. Había quienes cargaban con velas, dulces, flores, jarros de bebidas alcoholicas, pasteles y frituras calientes o frías, cebollas, pimientos, ajos y maíz. Algunas llevaban recipientes de sal a la cabeza, otras portaban grandes haces de tabaco y manojos de cigarros. Aqui se acercaba una, sobre un asno cuyas árganas iban cargadas de huevos y gallinas, por allá otra, trayendo por el mismo medio melones y sandías, higos o naranjas, para la venta.

Muchas cargaban caña de azúcar, ya pelada y cortada en trozos pequeños, listos para ser consumidos. Llegaban luego las carretas de los

- Ecole de Hautes Etudes - Paris. 
RIVAROLA, Milda. Placeras y mercaderas: La versión europen de la vida colidiana ca la antigua Asunción.

carniceros, con grandes trozos de carne sin clasificar, de animales carneados de cualquier modo, colgando de los carros cubiertos de paja (...).

Después de los grupos citados, venían los índios payaguaes, robusios y atléticos, con pescados colgando de largos remos que portaban al hombro. Los seguían otros indígenas, con manojos de chalas traídos desde el Chaco para pienso de los caballos de Asunción. Cuando lodos estos grupos - que sumaban, creo, unas quinientas personas - se congregaban en la plaza del mercado, empezaban a ubicarse en filas paralelas, dejando sólo el espacio suficiente para que los compradores Iransiten entre cllos.

No habia bancos, ni listas de precios: los artículos se exhibían sobre esterillas echadas en el suelo y los dueños se acuclillaban delrás. De loda la masa de vendedores, al menos tres cuartas partes cran mujeres, y otro tanto sucedía con las compradoras, de modo tal que el fondo era cubierto por una densa masa de figuras vestidas de blanco, conversando, charlando, dicutiendo y grilando en guaraní, mientras resonaba el zumboneo ruidoso de la vívida escena"1.

Las diferenciaciones sociales que empiezan a ser percibidas durante la "Primera República" ubican a las placeras en la úlitima categoría. El diplomático americano Washburn, describe los bailes ofrecidos durante el gobierno de F.S. López: "La última sección estaba ocupada por las clases más pobres - mujeres que se ganaban la subsistencia acarreando agua, manteniendo pequeños puestos de venta en el mercado, las de servicio doméstico, o con otros medios poco respetuosos de la decencia y la moralidad" $^{2}$.

Su descripción del mercado sólo difiere de la de los Robertson en to referente a la pulcritud de las mujeres, tema que será recurrente en otros observadores exiranjeros: "La principal plaza, o la plaza del mercado, en Asunción, estaba situada en el centro mismo de la ciudad, y en las claras y soleadas mañanas ofrecía un aspecto de lo más atractivo. El mercado de la carne, usualmente monopolizado por un miembro de la familia López, se situaba en un gran edificio de adobe enfrente de la plaza, pero todos los demás productos comestibles eran ofrecidos a la venta en el mercado abierto. Las carretas venían de la campaña por las noches, cargadas de maiz, naranjas, sandías, leña y miel de caña, y se alineaban en la madrugada a un costado de la plaza, of reciendo su carga a la venta.

1 ROBERTSON, J.A. \& W.P. Letters on Paraguay comprising an accoumt of a four yenrs residence in that republic, under the government of the Dictator Frcotia. London: J. Murnay, 1838, pp. 293-295 del I Tumo.

2 WASHBURN, C.A The history of Paragum; nith notes of persanal dusenrtions and reminiscences of Diplomncy under difficuhies. Boston: Lee \& Shepard Pub, 1871, vol. II, p. 100. 
R. IItstúria,-Sao Paulo, n. 129-131, p. 133-139, ago.-dez/93 a ago.-dez./94.

Decenas de mujeres venían también por las noclies; montando burros con las árganas cargadas de chipa, gallinas, huevos, mandioca y cualquier otra cosa que pudieran vender en la capilal. Una vez descargados los animales, cada mujer ocupaba su lugar en la plaza colocando frente suyo las mercaderías. estas mujeres se preciaban general mente de su atuendo pulcro y elegante. Las vestimentas sucias, con las que debieron haber caminado en la noche anterior unas 20 millas trayendo sus escasos productos al mercado, eran cambiadas por otras, blancas y limpias.

El número de mujeres (...) oscilaba entrc cuatrocientos a quinientos, y desde la madrugada hasta las ocho o nueve de la mañana la escena era de las más peculiares y bulliciosas que puedan imaginarse"3.

El mercado-guazú asunceno recordaba fuertemente a las ferias medievales, o los zocos orientales donde el intercambio no monelario era la regla. Bajo el gobierno de C.A. López, la circulación de moneda era aún excepcional, y la mayor parte del comercio se realizaba a través del ancestral sistema de trueque, incluso en la capital. El médico Demersay sufrió él mismo las consecuencias, "ya que nada hay mís primilivo que la manera en que los habitantes hacen sus adquisiciones en el mercado de Asunción, comprando un real de carne y cambiando luego trozos de clla por máz, mandioca; o naránjas" a las mercåderas ${ }^{4}$.

Las primeras manifestaciones colectivas de mujeres surgirán recién en la década del 70 , pero entre los escasos indicios de disidencia política durante la Guerra Grande, existen informes diplomálicos sobre las quejas expresadas por las mercaderas contra el rigor del reclutamiento militar.

Luego de las terrotas sufridas por el ejército paraguayo en Yatay y en Uruguayana, a mediados del 1865, "Las mujeres que forman casi exclusivamente el resto de la población <no llamada bajo armas> comienzan a hablar con bastante liberlad para lo que es el Paraguay, y a decir que el Presidente es el culpable de que la Mano de la Providencia haya caído lan duramenle sobre el país" (...).

"Se acaban de embarcar hacia Humaitá los reclulas precedentemente eximidos, como los tuertos, los cojos, etc. Cuando éstos aparecieron en ta plaza del mercado a hacer sus úllimas compras antes de partir, hubo una exclamación general de lástima en todas las mujeres, quienes decían abiertamente que se estaba enviando estos pobres desgraciados al matadero.

3 Ibic., pp. 227-228.

4 . DEMERSAY, L A. Histoire physiqu, cconomique et politique du Paragury et des établissements des Jésuites. Paris: I lachette, 1860/65, Tome II, Pp 175-176. 
RIVAROLA, Milda. Placeras y mercaderas: La versión europea de la vida culidiana en la antigua Asuncióo.

Lo que indica como la opinión pública eslá sobrepasada por la desgracia y la desesperación, es el hecho que la policía no pudo casligar a nadie, ya que todo el mundo era culpable. Hace apenas unos meses, la míni ma manifestación similar hubiera provocado apaleamicnlos y teportaciones en masa al Chaco" 5 .

Si la mayorfa de las mereaderas cran de sexo feminino anles de la guerra, al final de la misma ya no se ven hombres - ni indígenas - en el Mercado Guazú. El Gobierno entregó la concesión de los Merciılos (cl Mercado Central y el del Puerto) a Octavio 1. Molinas en 1870, autorizánclolo a cobrar impuestos y alquileres a las placeras cn compensación del capital inverlido en la construcción de los edificios, que fueron terminaklos en mayo de $1871^{6}$.

El atuendo femenino, $y$ el ancestral hábito del labaco continúan llamando inevilablemente la alención de los extranjeros, quienes empiezan a hacer curiosas valoraciones estélicas. Una viajera inglesa los describe en la inmediata posguerra. "Las mujeres visten poca ropa. Súlo una larga biusa blanca, generalmente bordadia en la parte superior y alada en la cintura. Algunas lucen curiosos y antiguos collares y peinetas de oro, todas van descalzas, y en ocasiones hacen 15 o 20 leguas de caminala diaria, cargando provisiones en la cabezal (...).

En las madrugadas el mercalo se llena de mujeres que van a vender sus mercaderías, Cumando los horribles cigarros del país. Aquuí las mujeres fuman desde la infancia, y todas parecen felices y conlentas, incluso quando la mayoría carce de un simple teclio yue las albergue"

Según Gabriel Carrasco, un intelectual español llegado a fines del siglo pasado: "Este país, víclima de la más cruenla de las guerras, ha vislo desaparecer casi loda su población masculina, de manera que los principales trabajos y el comercio de menudeo, es reálizado por mujeres (...)

La coquetería femenina no pierde sus derechos ni aún en medio de un mercado: muchas de las vendedoras eslaban adornidas de flores, con claveles y rosas prendidas entre sus abultadas trenzas. El cigarro, vicio orgánico de la mujer paraguaya de clases bajas, afcaba sus bocas, de las cuales salfan torrentes de humo!".

5 Laweal-Cochetet a Drouyn de L'IIuys. Asuncioin, 7 de octubre de 1865, Despacho N2 47 at Departamiento Polfítico del Ministerio de Relaciones Exteriores Francts. Quai J'Orsay, Assomption, Correspondratce Politiqute. Vol. IV.

6 Dictnmen y Bases det Con Irato de ln Municipalidad de Asunción, 16.VII. 1888 y 6.VIIl.1888, en VIULAGRA, lusé. Digesto de Ordenaizas, Reglamentos, Acuerdos, etc. de la Municipalidad de Aszención. Asunción: 'lip. La Opinión, 18\%6, pp. 129/13\% y 138/142.

7 MUIALL, Mrs M.G. From Europe to Parngumy and Mato-Grasso. Londua: E.Stanford, 1877 , pp 63/64. 
R. Illstórla, Squ Paulo, n. 129-131, p. 133-139, ago.-dez/93 a ngo.-dez./94.

Las vendedoras manifestaron desde Jos inicios una persistenle resistencia il pago de los impuesios municipales, y una medida del gobierno del Gral. Caballero intentallelo el cobro de estas lasas generó en 1880 un agresivo "movimiento de placeras", que despertó rápidamente críticas del diario capilalino La Reforma. El arliculista tralaba de "inoportunas" las qucjas de estas "ignorantes vendedoras", quienes así protestaban contra el procedimiento gubernativo. Las quejas no luvieron mayor cco, y el impuesto siguió pagándose, aunque en forma bastante irregular ${ }^{8}$. De hecho, las dos terecras partes de los ingresos de la Municipalidad de Asunción procedian en la época de los Mercados y del Matadero de Tablada, lo que dificulaba cualquier arreglo ante las prolestas reivindicalivas de estas Irabajadoras.

OIro viajero de finales del XIX, el [rancés Deiss, narra sus impresiones del mercado de la capilal que lenía apenas 22.000 habitantes en esos años. "Todos los trabajos son allí realizados por mujeres, vestidas siempre con una falda similar, sin corpiño, la blusa cerrada desde el nacimiento del cuello, casi flotante.

Si la vestimenta es simple, la coquelería encuentra sin embargo su expresión. Aros, brazalctes, peinetas decoradas con oro testimonian ampliamente que estas hijas de Eva no carecen de ciertas pretensiones. Algunas son hermosas. Pero su deteslible costumbre de fumar esos enormes cigarros, que machacan lodo el día entre los dientes, no les otorga ningún atractivo, al menos ante los ojos de un curopeo"'.

Una extensa descripción, no exenla de cicrio despectivo curocentrismo, es ofrecida por el inglés Th. Clitd, laciá 1890. "Para el artisła, Asunción interessa sobre lodo por los delalles de la vida al aire libre: él no debería perderse una visita al mereadelo cenlral, donde se encuentran reunidos cosi todos los tipos del país. En lat mainana, desde muy tempranas horas, el amplio espacio abierto que se extiende frenle al mercado eslí ya aliborrado de asnos, mulas de carga, carretas, yuntas de bucyes, perros y campesinos, llegados de la campaña a vender sus produclos y comprar provisiones. (...)

El mercado estai lleno de mujeres, unas viejas, olras jóvenes, todạs fumando o mascando un cigarro. Están vestidas, en su gran mayoría, de blanco; sólo algunas portan chales negros. Su ropa consisie en una falda de dos piezas superpueslas y una camisola alida en torno a la cintura, que deja el cuello al descubierto, y llevan encima un chal de algodón blanco que sirve de manta o de albornoz. Las mis coquetas complelan su "toiletle" llevando en la parte posterior de la cabeza una peinela de oro entre los cabellos,

8 LaReforma. Nsunción, IS.VII,1880.

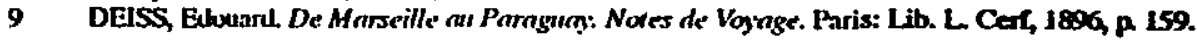


RIVAROLA, Milda. Placeras y mercaderas: La versión curopea de la vida colidiana en la antigua Asunción.

partidos usualmente, según la moda indígena, en dos largas trenzas. Todas cargan sus [ardos a la cabeza, independientemente del peso que tengan: he visto con mis propios ojos mujeres que se dirigían al Correo llevando sus cartus subre la cabeza (...).

En el interior del mercado se encuentran, además de los diferentes puestos dedicados a la venla de legumbres y las provisiones y mercaderías de toda especie, varios comedores donde aclivas malronas controlan grandes cacerolas en las que se cocinan humeantes guisos. A lo largo de los pasillos por donde circula el público, se forman grupos de mujeres de todas las edades, acuclilladas en el suelo. Son. en su mayoría, indigenas guaraníes, hay lambién algunas negras y mulalas. Todas Cuman, lienen un aspecto triste, aparencia delicada y lastimosa. y son, con raras excepciones, bastante feas. Se ve de cuando en cuando una joven guaraní de rosiro sereno y bellos ojos, bien formada y de aspeclo agradable, pero en conjunto sería difícil encontrar una colección más complela de mujeres viejas, escuálidas y feas que las del mercado de Asunción.

Eslas mercaderas son relativamente silenciosas y parecen indiferentes al liempo y a las cosas: permanecen senladas, con sus mercadorías distribuidas delante de cllas en el sueto. (...) Todas hablan con un tono quejumbroso y suplicanle, si se les pregunta el precio de sus mercancías, responden de lal forma que uno imagina que tienen lígrimas en la voz y dificultades en el hablar.

Se ven, en la galería exterior del mercado, grupos semejantes de mujeres jóvenes y ancianas acuclilladas delrís de sus pobres mercancías esparcidas en el suelo, esperando clientes. Otras se pasean silenciosas, los pies descalzos, indolentes y soñadoras, con el inevilable cigarro entre los labios. Sólo los zocos del Levante ofrecen imágenes semejantes a las del mercado de Asunción"10.

El pintoresquismo de estas narraciones que se repiten, casi idénticas, deja poco lugar a la memoria de la actividad gremial de estas mujeres. Mujeres que continuaron viviendo sin embargo su historia. Las autoridades municipales habían intenlado reprimir - en varias ocasiones - los comedores populares dentro del mercado, sin éxilo. los términos de la concesión municipal los próhibían explícilamente, y una ordenanza reiterando la interdicción de cocinar alimentos en el mercado №. 1 - el antiguo Mercado Guazú había sido desiruído en 1909 - provocó en 1918 otra reacción colccliva de las placeras. En número de cuatrocientas, estas se reunieron en

CHIL, Theodure. Les Républiques /lispano-Anéricaines. Paris: Lib. Illustree, 1891, pp. 414/416 
R. Histórla, Sấo Paulo, n. 129-131, p. 133-139, ago.-dez/93 a ago.-dez./94.

el domicio dc Andrea Ortega el 12 de noviembre de ese año, y decidieron ir a la "huelga general".

La prensa denunció violencias policiales contra las combativas mercaderas, algunos sindicatos anarquistas prestaron su apoyo - existía ya una Federación de Vendedoras del Mercado № 1 - y El Diario inició una agresiva campaña contra la gestión del intendente, quien debió presentar su renuncia. El edicto en cuestión fue revocado y se disminuyeron en un $50 \%$ los impuestos que grababan el comercio del mercado. Una multitudinaria manifestación de agradecidas mercaderas - portando docenas de flores recorrió poco después las calles asuncenas, desde el local de El Diario hasta la sede de la Sociedad de resistencia de Panaderos ${ }^{11}$.

Trás la belleza de la iconografía romántica de estas mujeres, se esconde, no menos atractiva, la trayectoria de su quehacer colectivo y cotidia lo pintoresco deja en ocasiones lugar a la historia.

ABSTRACT: This article's objective is w retrieve the daily life of female merchants of the city of Assunglo through the "Europenn vision" of eighteenth century travellers. The picturesque and popular are expressive elements in the narratives stressing the figure of the female indian. Besides describing habits and Iraditions, emphasis is given to the ways of cultural resistance expressed by these "silent" women "aloof to time and things".

KEY-WORDS: women, trade, travellers, violence, daily life.

11 Cronologí de S. Buzó Gómez, A. G. 09.01.033. El registra otra huelga de mercaderas en junio de ese afio. 